Bond University

Research Repository

\title{
Overcoming barriers to off-site construction through engaging stakeholders: A two-mode social network analysis
}

\author{
Gan, Xiaolong; Chang, Ruidong; Wen, Tao
}

Published in:

Journal of Cleaner Production

DOI:

10.1016/j.jclepro.2018.07.299

Licence:

CC BY-NC-ND

Link to output in Bond University research repository.

Recommended citation(APA):

Gan, X., Chang, R., \& Wen, T. (2018). Overcoming barriers to off-site construction through engaging stakeholders: A two-mode social network analysis. Journal of Cleaner Production, 201, 735-747. https://doi.org/10.1016/j.jclepro.2018.07.299

\section{General rights}

Copyright and moral rights for the publications made accessible in the public portal are retained by the authors and/or other copyright owners and it is a condition of accessing publications that users recognise and abide by the legal requirements associated with these rights.

For more information, or if you believe that this document breaches copyright, please contact the Bond University research repository coordinator. 


\section{Accepted Manuscript}

Overcoming barriers to off-site construction through engaging stakeholders: A twomode social network analysis

Xiaolong Gan, Ruidong Chang, Tao Wen

PII: $\quad$ S0959-6526(18)32288-1

DOI: $\quad$ 10.1016/j.jclepro.2018.07.299

Reference: $\quad$ JCLP 13753

To appear in: Journal of Cleaner Production

Received Date: $\quad 20$ January 2018

Accepted Date: $\quad 29$ July 2018

Please cite this article as: Xiaolong Gan, Ruidong Chang, Tao Wen, Overcoming barriers to off-site construction through engaging stakeholders: A two-mode social network analysis, Journal of Cleaner Production (2018), doi: 10.1016/j.jclepro.2018.07.299

This is a PDF file of an unedited manuscript that has been accepted for publication. As a service to our customers we are providing this early version of the manuscript. The manuscript will undergo copyediting, typesetting, and review of the resulting proof before it is published in its final form. Please note that during the production process errors may be discovered which could affect the content, and all legal disclaimers that apply to the journal pertain. 


\title{
Overcoming barriers to off-site construction through engaging stakeholders: A two-mode social network analysis
}

\author{
Xiaolong Gan", Ruidong Chang ${ }^{\mathrm{b} *}$, Tao Wen ${ }^{\mathrm{a}}$ \\ ${ }^{a}$ College of Economics and Management, Southwest University, Chongqing, China \\ ${ }^{\mathrm{b}}$ Centre for Comparative Construction Research, Faculty of Society and Design, Bond University, Gold \\ Coast, Australia \\ *Corresponding author. Email: rchang@bond.edu.au; Tel: 6155950158
}

\begin{abstract}
Rapid urbanization and the issue of environmental degradation compel developing countries to find a cleaner approach to replace or complement the traditional on-site construction method. Off-site construction (OSC) with various merits has been regarded as a promising approach to address the problems confronted in developing countries. However, promoting the adoption of OSC is indeed a tough task facing multiple barriers. It is the stakeholder collaboration integrating diverse resources scattered in the construction industry that can adequately address these barriers. Although multiple studies have been conducted from various perspectives, the issue of stakeholder collaboration, as the key to promoting the OSC adoption, has been overlooked. This research aims to explore stakeholders' influencing power over the barriers using twomode social network analysis. Firstly, 13 barriers to the OSC adoption, as well as 15 stakeholders with the power to overcome these barriers, were identified based on literature and expert judgments. Subsequently, a questionnaire survey was conducted receiving 39 responses from experts with rich experience in OSC in Chongqing, China. Centrality and core-periphery structure analyses were adopted to study the network. The results show that the government and developers have the highest degree centrality, betweenness centrality, and eigenvector centrality, and thus are the most influential stakeholders in the network. Similarly, the lack of knowledge and expertise, and the dominant conventional project process have the highest values of centrality among all barriers. With the density of interaction being 0.814 , core stakeholders and barriers have intensive relationships, and the network shows an apparent core-periphery structure. Theoretically, this study demonstrates the use of the two-mode social network in construction research, and practically, this study sheds lights on how to effectively drive the adoption of OSC in developing countries through promoting stakeholder collaboration.
\end{abstract}




\title{
Overcoming barriers to off-site construction through engaging stakeholders: A two-mode social network analysis
}

\begin{abstract}
Rapid urbanization and the issue of environmental degradation compel developing countries to find a cleaner approach to replace or complement the traditional on-site construction method. Off-site construction (OSC) with its various advantages has been regarded as a promising approach to address the problems confronted in developing countries. However, promoting the adoption of OSC is indeed a tough task that still faces multiple barriers. It is stakeholder collaboration by integrating diverse resources within the construction industry that can potentially address these barriers. Although multiple studies have been conducted from various perspectives, the issue of stakeholder collaboration, as the key to promoting OSC adoption, has been overlooked. This research aims to explore stakeholders' influencing power over such barriers using two-mode social network analysis. Firstly, 13 barriers to the OSC adoption, as well as 15 stakeholders with the power to overcome these barriers, were identified based on literature and expert judgments. Subsequently, a questionnaire survey was conducted comprising 39 responses from experts with rich experience in OSC in Chongqing, China. Centrality and core-periphery structure analyses were adopted to study the network. The results show that the government and developers have the highest degree centrality, betweenness centrality, and eigenvector centrality, and thus are the most influential stakeholders in the network. Similarly, the lack of knowledge and expertise, and the dominant conventional project process have the highest values of centrality among all barriers. With the density of interaction being 0.814 , core stakeholders and barriers have intensive relationships, and the network shows an apparent core-periphery structure. Theoretically, this study demonstrates the use of the two-mode social network in construction research, and practically, this study sheds lights on how to effectively drive the adoption of OSC in developing countries through promoting stakeholder collaboration.
\end{abstract}

Keywords: Off-site construction; barriers; prefabrication; social network analysis; China; stakeholders. 


\section{Introduction}

Global resources are being used up at an alarming rate, causing not just greenhouse gas emissions but also environmental degradation (Olubunmi et al., 2016). To a large extent, building activities with high energy consumption have contributed to various environmental issues (Lu et al., 2017; Teng et al., 2017). For instance, globally, the construction industry consumes $40 \%$ of total energy production, $12-16 \%$ of all water available, $32 \%$ of non-renewable and renewable resources, $25 \%$ of all timber, $40 \%$ of all raw materials, produces $30-40 \%$ of all solid wastes, and emits $35-40 \%$ of $\mathrm{CO}_{2}$ (Darko et al., 2017). Moreover, the extent of the impacts of building stock on the environment could be exaggerated due to the rapid urbanization and associated development activities in developing regions (Shi et al., 2015). On the one hand, according to Gan et al. (2017), the urban population in developing countries is expected to be 2.538 billion in 2050. Driven by migrations from rural to urban areas, massive housing construction will continue in the future. On the other hand, a number of problems confront the construction industry in developing countries, especially low productivity caused by the conventional cast in-situ method (Teng et al., 2017). It is not only inadequate in adjusting to increasing housing demands, but also at odds with the goals of improving environmental sustainability (Lovell \& Smith, 2010). Therefore, it is urgent to find a new approach not only satisfying surging housing demands timely but also alleviating environmental impacts associated with conventional construction methods.

The off-site construction (OSC), an idea borrowed from the manufacturing industry, is a construction approach in which a certain amount of building components are manufactured in a controlled environment, transported to the construction site and assembled into buildings (Mao et al., 2015). It is a radical innovation within the building sector as the construction methods for completing projects are entirely transformed (Steinhardt et al., 2013). Several advantages of adopting OSC have been reported, such as building faster, i.e., a 30-storey hotel erected in only 15 days (Gao \& Low, 2014), reducing embodied carbon and construction waste up to $34 \%$ and $74 \%$ respectively (Mao et al., 2013), cost saving up to 58\% (Arditi et al., 2000), and less labour requirement up to $30 \%$ (Jaillon \& Poon, 2008). The OSC adoption can not only meet the increasing demand for housing, but also improve the environmental sustainability of the construction industry. More importantly, it can facilitate the shifting of the construction industry from a labor-intensive to a "knowledge-based" industry (Nadim \& Goulding, 2011; O'Neill \& Organ, 2016). OSC is considered as an ideal alternative replacing the conventional construction method and addressing the challenge confronted by the construction industry in developing countries. 
The promotion of OSC adoption is indeed a tough task as the construction industry always lags behind other sectors in adopting technological innovations (Chang et al., 2017; Lovell et al., 2010; Nadim \& Goulding, 2010). In order to promote OSC adoption, a number of studies have been conducted from various perspectives, including (1) investigating the opportunities for OSC adoption (Arif \& Egbu, 2010; Nadim et al., 2010); (2) analyzing the status of OSC adoption (Ji et al., 2017); (3) examining the barriers to OSC adoption (Polat, 2010; Zhang et al., 2014); (4) examining the performance and impacts of OSC adoption in various aspects, such as cost, energy, construction waste, and life cycle performance (Hong et al., 2016; Kamali \& Hewage, 2016; Liu et al., 2014); (5) identifying complementary technologies for OSC adoption, such as Building Information Modelling, and Radio Frequency Identification (Li et al., 2017); (6) developing decision methods for OSC adoption (Pan et al., 2012a); and (7) exploring the business models, design, transportation, production, and assembly of OSC (Li et al., 2014b; Liu et al., 2016) These existing studies provide valuable information for developing countries in formulating policies to promote OSC adoption.

However, stakeholder collaboration as the key to promote OSC adoption has been overlooked by previous studies. Construction innovation involves multiple participants collaborating at the project level (Xue et al., 2014). The unique features of construction, e.g., one-of-a-kind nature of construction projects and temporary organization, seriously impede stakeholder collaboration for technology development in construction (Reichstein et al., 2005; Xue et al., 2017). Driven by selfinterest, traditionally stakeholders are more likely to invest scarce resources towards their individual goals rather than making a joint effort (Cheng et al., 2001). If undesired consequence happens, stakeholders tend to shirk from responsibilities and pass the responsibility to others (Saito \& Ruhanen, 2017). Thus, problems relevant to the adoption of innovative technology in construction largely stem from inadequate stakeholder collaboration (Dewick \& Miozzo, 2004). To establish effective stakeholder collaboration of OSC adoption, it is necessary to firstly clarify stakeholders' power in eliminating the associated barriers. Power is the key attribute reflecting stakeholders' ability to tackle certain issues in the industry (Lin et al., 2017). Powerful stakeholders should undertake the leading responsibility to deal with relevant barriers to OSC. Otherwise, conflicts could happen due to the imbalance between power and responsibility. Therefore, stakeholders should undertake the corresponding responsibility based on their power and capabilities, which is the prerequisite to establishing effective stakeholder collaboration for OSC adoption.

Few studies investigated the issue of stakeholder collaboration in OSC broadly, and the stakeholders' power to tackle the barriers to OSC specifically. With the aim to fill this gap of 
knowledge, this study adopts a stakeholder-barrier analysis to identify stakeholders' power status on the barriers to OSC adoption using a two-mode social network approach. The specific objectives of this study are outlined as follows:

(1) to identify the related stakeholders and barriers to OSC adoption;

(2) to explore the stakeholders' power status over the barriers to OSC adoption;

(3) to investigate the network characteristics of stakeholder collaboration and depict the network structure.

Unlike traditional social network analysis examining the interrelationships within the same set of entities (one-mode network analysis), the two-mode network analysis explores the relationships between two sets of entities. Therefore, it is able to demonstrate the stakeholders who are linked with each other through the barriers that they could jointly tackle, as well as the barriers that are linked with each other through the stakeholders who have the power to influence them. Consequently, not only the network characteristics of stakeholder collaboration can be revealed, but also a roadmap for stakeholder collaboration to promote OSC can be depicted. The innovative perspective of this study sheds light on supporting the development of OSC not only in China but also other developing countries.

\section{Literature review}

\subsection{Barriers to the OSC adoption}

The key feature of OSC is the relocation of most building activities from onsite to an offsite factory (Polat, 2008; Zhai et al., 2014). Despite its significant benefits, OSC development remains slower than anticipated. Several studies have been undertaken to explore the barriers to OSC adoption across various countries. Drawn on previous studies such as Chang et al. (2016), a directed content analysis of the literature for identifying these barriers was conducted in a systematic manner. Firstly, related journals and conference articles were searched in the databases of "Web of Science", "Compendex Engineering Village" and ASCE library using some combinations of keywords such as "barriers", "factors", "offsite construction", "prefabricated construction", "precast concrete building", "modern methods of construction", "industrialized building", and "offsite prefabrication". The retrieved articles were further screened through reviewing their abstracts and conclusions to determine their relevance to this study. Then, content analysis was employed to analyze the selected articles based on the TOE (TechnologyOrganization-Environment) framework. This framework has been extensively adopted in the 
studies of construction innovation (Nadim et al., 2011; Xue et al., 2017). According to this framework, the barriers to OSC adoption were summarized into three perspectives, namely technological barriers, organizational barriers, social and market barriers.

\subsubsection{Technological barriers}

The immature technology of OSC could lead to various aspects of issues related to cost, logistic, quality, and aesthetic performance. Firstly, there is a general census that higher cost is one of the most influential factors impacting the adoption of OSC (Elnaas et al., 2014). The higher cost is caused by the manufacturing, procurement, transportation, design, and installation process of OSC (Mao et al., 2016; Polat, 2008). Besides, the required skill laborers with a high wage as well as their related education and training also induce higher cost, especially in developing countries where the lack of qualified labor is common (Chiang et al., 2006; Zhai et al., 2014).

The issues of logistics inhibiting OSC adoption mainly include limited placing space for storage due to seasonal demand, the lack of on-site storage area, and the constraints of transportation (Pan et al., 2012a; Tam et al., 2007). As Chiang et al. (2006) argued, most manufacturers set their fabrication yards in remote areas for saving cost, which leads to longer transportation routes. This may cause severe delays in the delivery of prefabricated components to the construction site (Polat, 2010).

Even though high quality has been considered as one of the drivers for promoting OSC adoption, there are low-quality products in the market which have been regarded as a prominent factor hindering wider adoption (Kamali et al., 2016). The problems of cracks and water leakages, such as wall insulation cracking and pipe leakage in kitchen areas, have been reported on some OSC projects, causing many disputes between buyers and developers (Zhang et al., 2014). Similarly, research by Lovell et al. (2010) indicated that poor durability inhibited the extensive adoption of OSC.

Regarding the aesthetic performance of buildings, the tendency towards repetitiveness has been highlighted in OSC (Arditi et al., 2000). As Jaillon and Poon (2010) indicated, the variations in architectural design are less frequent when adopting OSC. The architectural creativity also might suffer due to the transportation constraints when a significant amount of bulky and heavy components are required (Polat, 2008).

\subsubsection{Organizational barriers}

The organizational barriers are related to the organizational capability to adopt OSC, which denotes the management, process, knowledge, and business model of the organization. The 
traditional project process dominated in the construction industry is unsuitable for adopting OSC (Blismas \& Wakefield, 2009; Nadim et al., 2010). The adoption of OSC requires much more time in the pre-project planning and early stakeholder participation, which conflicts with current project process (Jaillon et al., 2010; Kamali et al., 2016; Zhai et al., 2014). Meanwhile, several challenges of management have been identified. OSC adoption involves multiple parties, and a high level of integration among partners is required (Luo et al., 2015). However, the poor collaboration caused by the fragmented nature of the construction industry has been regarded as one of the key barriers to adopting OSC. It is challenging to develop collaborative relationships between stakeholders in a project-based industry (Steinhardt et al., 2013; Xue et al., 2017).

The lack of manufacturers and suppliers has been argued as a major barrier to adopt OSC as well (Mao et al., 2015). Manufacturers in developing countries are often without adequate financial resources for quality control procedures, resulting in product quality problems in practice (Polat, 2010). Lacking knowledge and expertise has been criticized as a barrier affecting OSC adoption. This is mainly because current civil engineering and architecture curriculum rarely provides thorough coverage of OSC (Arditi et al., 2000). Meanwhile, insufficiently qualified workers might lead to severe problems such as inferior structural performance (Polat, 2010). Besides, the dominant importance of land acquisition in housing development to generate profits leads to less attention paid to the construction process (Pan et al., 2008). The adoption of OSC requiring high upfront payments reverses the existing funding models in the construction industry (Steinhardt et al., 2013). This could result in tremendous economic pressure for residential developers.

\subsubsection{Market and social barriers}

The adoption of OSC is also constrained by the external environment in which facilitating conditions are insufficient. For instance, the limited market demands could cause enormous difficulty in achieving a return on investment, which could lead to difficulty in obtaining funding from financial institutions (Arditi et al., 2000). Lack of codes and standards could make prefabricated buildings hard to be designed as component manufacturers cannot match the assembly process onsite (Mao et al., 2015). The issues of social acceptance are related to the negative perception of prefabricated housing in public (Luo et al., 2015). This could lead to client skepticism and resistance, reducing the demand for prefabricated buildings (Mao et al., 2015). Similarly, the risk-averse culture of the construction industry can resist technological innovations by protectionism and conservatism (Nadim et al., 2010). The public policies and regulation instruments play a critical role in facilitating the adoption of OSC. Policies and regulations have been argued to focus rarely on OSC adoption (Luo et al., 2015). Meanwhile, there are no local 
incentive measures, such as tax relief measures or strategies for municipal construction cost to encourage the adoption of OSC (Zhang et al., 2014).

\subsection{Power in stakeholder collaboration}

With stakeholder theory moving from a dyadic perspective to a network perspective, stakeholder collaboration has been emphasized as the new aim of stakeholder management (Missonier \& Loufrani-Fedida, 2014). Stakeholder collaboration refers to the process where a group of autonomous stakeholders participate in a problem domain, using shared rules, norms, and structures, to act or decide on issues related to that area (Wood \& Gray, 1991). Due to the characteristics of autonomous stakeholders, factors such as different and competing interests, contradicting viewpoints, and complex relationships could hinder the collaborative process (Saito et al., 2017). As the success of stakeholder collaboration is mainly dependent on coordinating the voice of stakeholders, it is necessary to understand their salience in the collaborative process. The knowledge of stakeholder salience contributes to effective stakeholder coordination, the inclusion or exclusion of stakeholders in cooperative actions, and the categorization of their roles in certain projects (Saito et al., 2017).

Power is one of the most critical attributes based on the stakeholder salience model proposed by Mitchell et al. (1997). Power has been defined as the capacity of one social actor to change others' behavior towards one's intentions regardless of resistance (Gaski, 1984). Regarding stakeholder collaboration, stakeholders' power can stem from their attributes and their structural position (Tiew et al., 2015). The power from an individual attribute can be explained by the resources dependency perspective (Mitchell et al., 1997), in which stakeholders' power in collaboration is determined by the resources the stakeholders possess (Saito et al., 2017). A stakeholder in control of essential and critical resources possesses a power advantage relative to other stakeholders in the collaboration (Mitchell et al., 1997). Similarly, the power from structural positions is emphasized by the network perspective of stakeholders (Rowley, 1997). Stakeholders' power advantage could come from the positions they occupy in the network, if they control information and knowledge flow in the system or have easy access to critical resources within the network. The resource dependency perspective and network perspective of stakeholder power complement each other, highlighting that to understand stakeholder power, it is necessary to investigate stakeholder positions and relationships in the collaborative network, as well as their attributes and owned resources.

To summarize, previous studies have revealed that various barriers related to the technology, organization and social environment of OSC have hindered the further uptake of OSC. 
Meanwhile, previous studies on stakeholders' power and stakeholder collaboration suggest the more powerful a stakeholder is, the stronger influence the stakeholder can exert to the problem domain. Few existing studies have investigated how to effectively eliminate the various OSC barriers, which apparently cannot be achieved without relevant stakeholder actions. To overcome the barriers to OSC efficiently, different resources need to be provided by various stakeholders working collaboratively. Therefore, it is of high importance to investigate stakeholders' influencing power over the various barriers to OSC.

\section{OSC policy in Chongqing, China}

Chongqing is located in the Southwestern part of China on the upper stream of the Yangtze River as shown in Fig. 1. As the nation's newest municipality, Chongqing is of strategic importance to the development of Western China. Rapid urbanization and economic development have put Chongqing in a favorable situation to promote OSC adoption, and the development of steel structure prefabricated buildings has been highlighted by the issued government plan "Guidance on Accelerating the Application of Steel Structure and Development of Industrial Innovation". In 2015, the GDP growth rate of Chongqing was $11 \%, 4.1 \%$ higher than the national average. The steel and automobile industries are the pillar industries in Chongqing, demonstrating that Chongqing has possessed the required manufacturing capability needed for the promotion of OSC (Arif et al., 2010). Furthermore, the urbanization rate is expected to rise from $60.9 \%$ in 2015 to above $75 \%$ in 2030 according to the "Population development Plan of Chongqing City (20162030)" issued by Chongqing Municipal Government in 2017. This suggests that there will be a high volume of housing building practices in Chongqing in the future. Additionally, Chongqing Municipal Government has issued various policies to promote OSC adoption. For instance, all public housing should adopt OSC from 2017 according to the "Opinions on Accelerating the Modernization of the Construction Industry" issued by Chongqing Municipal Government in 2015 . 




Fig. 1. The location of Chongqing city and main data.

According to the Chongqing Urban-rural Construction Committee, new buildings adopting OSC in Chongqing currently account for less than $5 \%$ of new building construction, which is far below the policy goal of $20 \%$ by 2020 . This implies that the traditional on-site construction approach is still dominant in Chongqing. Based on the "Guidelines on the Development of Prefabricated Buildings" released by Chinese State Council in 2016, OSC adoption has been considered as a national policy to boost the modernization of the construction industry. This suggests that great efforts should be made by each municipal or provincial government to achieve the policy goal of OSC adoption. Under this circumstance, it is urgent to not only explore what issues affect OSC adoption, but also identify who has the power to tackle these issues that currently impede the promotion of OSC adoption.

\section{Research methodology}

This study aims to explore the stakeholders' influencing power over the barriers to OSC through a questionnaire survey. To meeting this target, firstly, the barriers to OSC and related stakeholders were identified, followed by the development of a questionnaire survey to investigate stakeholders' power to address different barriers. Finally, the two-mode social network was employed for data analysis. 


\subsection{Identification of stakeholders and barriers}

In order to identify the barriers to OSC and related stakeholders, two methods were used, namely literature review and expert interview. A total of 13 barriers were initially identified after the literature review process. Similarly, an initial list of 13 groups of stakeholders with the power to facilitate the elimination of these barriers was also identified with reference to Teng et al. (2017) and $\mathrm{Li}$ et al. (2016). The 13 types of stakeholders include developers, supervisors, designers, manufacturers, government, contractors, researchers, financial institutions, higher education institutions, consultants, the public, suppliers of material \& equipment, and logistics enterprises. It should be noted that previous studies have mentioned other stakeholders who were not examined in this study. For instance, Jeong et al. (2009) highlighted the role of retailers in coordinating the delivery and installation of prefabricated buildings, which in China is generally undertaken by developers (Jiang et al., 2016).

In order to confirm the validity and reliability of the identified stakeholders and barriers relevant to OSC adoption, a pilot study was conducted. Initially, a list of 25 experts was suggested by the Centre of Chongqing Construction Technology Development which is responsible for the promotion of construction innovation in Chongqing. Subsequently, an invitation letter for participating in the pilot study was sent to these experts, and eight indicated their willingness to participate. All of the eight experts had more than eight years of experience studying or working in the field of OSC. Three experts were from universities holding professor positions. One expert works as a local construction authority leader. The remaining four experts include an engineer in Chongqing Yulong Hangxiao Steel Structure Corporate Ltd, a manager in China Vanke Real Estate Co., Ltd, a designer director in Chongqing Architectural Design Institution and a project manager in Chongqing Construction Engineering Group Corporate Ltd, representing the stakeholders of manufacturers, developers, designers, and contractors respectively.

The 13 barriers, as well as the 13 types of stakeholders identified in the literature review, were sent to the eight experts through email for their comments and suggestions. The experts were asked to answer the following questions: (1) Are there any barriers or stakeholders identified from the literature review that are not relevant to OSC? (2) Are these barriers and stakeholders expressed properly and understandably? (3) Are there any additional barriers or stakeholder groups that could be added? The responses indicate that the experts' opinions are strongly aligned with the barriers identified in the literature review. All the 13 barriers were selected as critical barriers by the experts, as shown in Table 1. The experts also acknowledged the 13 stakeholder groups identified initially, but they suggested another two types of stakeholders should be added, 
namely the media and professional sub-contractors. Therefore, there are a total of 15 stakeholder groups, including S1 (the government), S2 (developers), S3 (designers), S4 (contractors), S5 (professional sub-contractors), S6 (supervisors), S7 (manufacturers), S8 (researchers), S9 (education institutions), S10 (consultants), S11 (suppliers of equipment and materials), S12 (financial institutions), S13 (the public), S14 (logistic enterprises) and S15 (the media).

Table 1. Barriers affecting the OSC adoption

\begin{tabular}{lll}
\hline Code & \multicolumn{1}{c}{ Factors } & \multicolumn{1}{c}{ Key References } \\
F1 & High cost & (Mao et al., 2015; Polat, 2010; Zhang et al., 2014) \\
F2 & Inefficient logistics & (Chiang et al., 2006; Pan \& Goodier, 2012b; Polat, 2010) \\
F3 & Poor manufacturing capability & (Mao et al., 2015; Polat, 2008; Steinhardt et al., 2013) \\
F4 & Quality issues & (Lovell et al., 2010; Zhang et al., 2014) \\
F5 & Poor aesthetic performance & (Arditi et al., 2000; Jaillon et al., 2010; Zhai et al., 2014) \\
F6 & Dominance of conventional project process & (Blismas et al., 2009; Nadim et al., 2010) \\
F7 & Lack of codes and standards & (Arditi et al., 2000; Mao et al., 2015) \\
F8 & Complicated management & (Luo et al., 2015; Steinhardt et al., 2013; Xue et al., 2017) \\
F9 & Lack of knowledge and expertise & (Arditi et al., 2000; Polat, 2008, 2010) \\
F10 & Inappropriate business model & (Pan et al., 2012b; Steinhardt et al., 2013) \\
F11 & Limited market demand & (Arditi et al., 2000; Nadim et al., 2010) \\
F12 & Lack of social acceptance & (Luo et al., 2015; Mao et al., 2015; Polat, 2010) \\
F13 & Inadequate policies and regulations & (Jaillon et al., 2010; Luo et al., 2015; Zhang et al., 2014) \\
\hline
\end{tabular}

\subsection{Data collection}

In order to explore the power status of identified stakeholders over the barriers to OSC adoption, a full questionnaire survey was subsequently conducted. Various existing studies have adopted the method of questionnaire survey as an effective approach for collecting stakeholders' perspectives and opinions relevant to OSC adoption (Zhang et al., 2014). In this study, the full questionnaire has three sections. A brief introduction of this study was provided at the beginning of the questionnaire, followed by a section designed to collect the basic information of respondents including their organization type, job position, and years of working experience relevant to OSC. In the final section, respondents were required to evaluate whether the 15 stakeholder groups have the power to influence each of the 13 barriers by using 1 (Yes) or 0 (No).

The target respondents of the questionnaire survey were limited to experienced practitioners in OSC adoption. In order to increase the sample size, the snowball sampling technique was adopted in this study. Enabling the approach to a large population through the respondents' social networks, snowball sampling is particularly useful when the required respondents need to have 
relevant experience in certain fields (Luo et al., 2015; Mao et al., 2015). Initially, the eight experts participating in the pilot study were invited to help distribute the questionnaire among their colleagues, business partners, and senior practitioners whom they know possess abundant knowledge and experience in OSC. Similarly, the respondents were encouraged to distribute the questionnaire to their colleagues after they filled the questionnaire, thereby fulfilling the requirements of the snowball sampling technique. The questionnaires were sent to the respondents through an online form using the largest academic online survey platform in China, i.e., www.sojump.com. Web surveys have been extensively adopted in construction studies as well as previous studies on OSC adoption (Rahman, 2013).

Table 2. Profiles of respondents

\begin{tabular}{|c|c|c|}
\hline Profile & Number & Percentages \\
\hline \multicolumn{3}{|l|}{ Organization type } \\
\hline Government & 3 & $7.7 \%$ \\
\hline Academic & 7 & $17.9 \%$ \\
\hline Developer & 3 & $7.7 \%$ \\
\hline Consultant & 3 & $7.7 \%$ \\
\hline Contractor & 5 & $12.8 \%$ \\
\hline Manufacturer & 4 & $10.3 \%$ \\
\hline Designer & 5 & $12.8 \%$ \\
\hline Supervisor & 4 & $10.3 \%$ \\
\hline Research institution & 5 & $12.8 \%$ \\
\hline \multicolumn{3}{|l|}{ Job position } \\
\hline Professor and associate professor & 7 & $17.9 \%$ \\
\hline Project manager & 6 & $15.5 \%$ \\
\hline Engineers & 7 & $17.9 \%$ \\
\hline Senior manager & 9 & $23.1 \%$ \\
\hline Chief manager & 5 & $12.8 \%$ \\
\hline Director & 5 & $12.8 \%$ \\
\hline \multicolumn{3}{|l|}{ Years of experiences in OSC } \\
\hline$<2$ & 0 & 0.00 \\
\hline $2 \sim 5$ & 15 & $38.5 \%$ \\
\hline $5 \sim 10$ & 16 & $41.0 \%$ \\
\hline$>10$ & 8 & $20.5 \%$ \\
\hline
\end{tabular}

The questionnaires were disseminated in Chongqing from April to Jun 2017. 184 potential respondents relevant to OSC received the online questionnaire, and 39 valid responses were obtained, with the returning rate of $21.2 \%$. It is very normal that construction studies have a response rate between $20 \%$ and $30 \%$ (Hwang et al., 2018). The profiles of respondents were presented in Table 2. 61.5\% of the respondents had more than 5 years' experience in OSC adoption, including $20.5 \%$ of respondents with over 10 years of experience. $17.9 \%$ of the 
respondents are professors or associate professors. Other responses are from project managers (15.5\%), engineers $(17.9 \%)$, senior managers $(23.1 \%)$, chief managers $(12.8 \%)$ and directors $(12.8 \%)$. The respondents represent various stakeholders such as developers and designers, as shown in Table 2. The balanced respondent profile reduces the questionnaire bias and improves the representativeness of the sample (Chang et al., 2017).

\subsection{Two-mode social network analysis}

Collaboration networks are characterized by a set of actors and the interrelationships among the actors (D'Esposito et al., 2014). One-mode networks consider only homogeneous nodes, which may not be sufficient to describe the complex relationships of collaborative networks accurately. This give rises to the two-mode network analysis, which is a particular form of a complex network whose nodes can be divided into two different sets, and ties are only developed between nodes belonging to the different sets. The two-mode social network was adopted in this study for data analysis by taking the 13 barriers and 15 related stakeholders as two-mode sets. Similar to previous studies using two-mode network analysis (Aitkin et al., 2014; Weng et al., 2014), three steps of two-mode social network analysis were conducted as noted below.

\subsubsection{Constructing the stakeholder-barrier adjacency matrix}

The element of stakeholder-barrier adjacency matrix refers to the stakeholders' power status over the barriers. The stakeholder-barrier adjacency matrix (A) is formed by a set of stakeholders (X) as well as a set of barriers (Y). $X_{i}$ represents each of the identified 15 stakeholders; $Y_{j}$ represents each of the 13 barriers; and $a_{i j}$ represents whether stakeholder $X_{i}$ has the power to tackle barrier $Y_{j}$, defined as follows:

- $\quad a_{i j}=1$, barrier $Y_{j}$ can be addressed by stakeholder $X_{i \text {; }}$

- $\quad a_{i j}=0$, barrier $Y_{j}$ cannot be addressed by stakeholder $X_{i}$

In stakeholder-barrier adjacency matrix, if two stakeholders have the power to address the same barrier, these two stakeholders can be regarded as co-attended which can be captured by the coattended stakeholder-stakeholder matrix. The stakeholder-stakeholder matrix is constructed by calculating the co-attended barriers between stakeholders. According to Li et al. (2014a), the coattended barrier $w_{i j}$ between the stakeholder of $x_{i}$ and $x_{j}$ is calculated by the formula (1):

$$
w_{i j}=\left\{\begin{array}{l}
\operatorname{card}\left(X_{i} \cap X_{j}\right), i \neq j \\
0, i=j
\end{array}\right.
$$

where $X_{i}$ refers to the set of the barriers that can be addressed by stakeholder $x_{i}$, and $X_{j}$ refers to the set of the barriers that can be addressed by stakeholder $x_{j}$.

The $i j$ th element in stakeholder-stakeholder matrix can be defined as the number of barriers over which stakeholder $i$ and stakeholder $j$ both have influencing power to address. This value can be 
interpreted as the power similarity of different stakeholders, suggesting their collaborative potentials (Borgatti et al., 1997). A barrier-barrier matrix could be similarly developed, with the $i j$ th element in the barrier-barrier matrix representing the number of stakeholder groups who have power over both barrier $i$ and barrier $j$. This can be interpreted as resource similarity between the two barriers.

\subsubsection{Visualizing and measuring the stakeholder-barrier network}

Based on the stakeholder-barrier adjacency matrix, the visualization of stakeholder-barrier network can be developed through use of the UNCIENT software. Subsequently, the relative positions of the nodes in the stakeholder-barrier network can be determined by calculating the degree centrality, betweenness centrality, and eigenvector centrality of the nodes (Table 3).

Table 3. Descriptions of degree centrality, betweenness centrality, and eigenvector centrality

\section{Descriptions}

- Degree centrality defines the number of ties that a node has with other nodes

- Betweenness centrality is determined by the number of other nodes a node is connected to, when these other nodes are not connected to each other.

- Eigenvector centrality is a weighted degree measure in which the centrality of a Borgatti and Everett (1997) node is proportional to the sum of the centrality of the nodes it is adjacent to.

Degree centrality is a measure of immediate connectivity or popularity of a node and its vulnerability to catching whatever flows through the network (Sankar et al., 2015). In the stakeholder-barrier network, the degree centrality of a stakeholder is the number of barriers that the stakeholder has the power to address, and similarly, the degree centrality of a barrier is the number of stakeholders who have the power to address the barrier. According to Malik et al. (2017) et al., degree centrality can be measured by formula (2):

$$
C_{D}(K)=\operatorname{deg}_{k}=\sum_{j}^{N} A_{k j}
$$

where $\mathrm{K}$ is the focal node, $\mathrm{j}$ represents other nodes, $\mathrm{N}$ is the total number of nodes, $\mathrm{A}_{K j}$ is the element of the stakeholder-barrier adjacency matrix.

Betweenness centrality is an indicator of a node's strategic position in the network, implying its ability to change or hinder the flow of information through it (Martinus et al., 2015; Sankar et al., 2015). It captures the capacity of an actor to play the role of an intermediary in the network (Weng et al., 2014). With reference to Faust (1997), in stakeholder-barrier network, the betweenness centrality of the barrier can be expressed that pairs of stakeholders meet only in that barrier, and betweenness centrality of stakeholder refers to a pair of barriers only can be addressed by that stakeholder. The betweenness centrality can be calculated by the formula (3):

$$
C_{B}(i)=\sum_{j}^{N} \sum_{K}^{N} \frac{g_{j k}^{w}(i)}{g_{j k}^{w}}, j \neq k
$$

where $g_{j k}$ is the total number of binary shortest paths or routes between two nodes, and $g_{j k}(i)$ is the 
number of those routes that pass through node $k$.

Eigenvector centrality determines how well connected are the nodes to which a given node is connected, and measures the influence of a node in the network (Sankar et al., 2015). In stakeholder-barrier network, the eigenvector centrality of stakeholders is determined by the sum of the centralities of the barriers that stakeholders have the power to address, and the eigenvector centrality of the barrier is determined by the sum of centralities of stakeholders who have the power to address. According to Borgatti et al. (1997), the eigenvector centrality of a node in the network can be measured by formula (4):

$C_{e}=\sqrt{\frac{1}{2 n_{\mathrm{o}}}}$

where $n_{0}$ is the size of the vertex set that the node belongs to.

\subsubsection{Analyzing the structure of the stakeholder-barrier network}

In a core-periphery network structure, there is a cohesive group of core actors and a set of peripheral actors that are loosely connected to the core group (Borgatti \& Everett, 2000). Regarding the stakeholder-barrier network, stakeholders in core position are the key stakeholders who can be considered as network coordinators (Cattani \& Ferriani, 2008). The delineation of the core/periphery zones is based on the comparison between an ideal structure from the available network data and the actual structure (Muinz García \& Carvajal, 2006). The ideal structural can be regarded as a generalization of the maximally centralized graph of Freeman (1978), namely a single node is connected to all other nodes, which are not connected to each other (Borgatti et al., 2000). Regarding this, the core-periphery network structure can be examined by formula (5) together with formula (6):

$$
\begin{aligned}
\rho & =\sum_{i, j} a_{i j} \delta_{i j} \\
\delta_{\mathrm{ij}} & =\left\langle\begin{array}{l}
1 \text { if } \mathrm{c}_{i}=\text { core or } \mathrm{c}_{j}=\text { core } \\
0 \text { otherwise }
\end{array}\right.
\end{aligned}
$$

where $a_{i j}$ refers to the presence or absence of a tie in the observed data, $c_{i}$ indicates the class (core or periphery) that node $i$ is classed to, and $\delta_{i j}$ represents the presence or absence of a tie in the ideal structure.

\section{Results}

\subsection{Stakeholder-barrier adjacency matrix}

The power status of stakeholders over a particular barrier is confirmed when more than $80 \%$ of the total respondents, which is 32 in this study, believe the stakeholder groups have influencing power over that barrier. This principle has been used by Shen et al. (2016) to conduct similar research. 
The developed stakeholder-barrier adjacency matrix is shown in Table 4. Regarding the influencing power of different stakeholder groups, Table 4 indicates S1 (the government) has the power to address the highest number of barriers (12 barriers) among all the stakeholder groups, followed by S2 (developers) and S7 (manufacturers). Similarly, regarding the required stakeholders to address the barriers, F9 (lacking knowledge and expertise) requires the highest number of stakeholder groups (12 groups) to address it, followed by F6 (dominance of conventional project process) and F8 (complicated management). Six stakeholder groups including S1 (the government), S2 (developers), S3 (designers), S4 (contractors), S5 (subcontractors), and S7 (manufacturers) have high power over technological barriers (F1, F2, F4, and F5). Each stakeholder has the power to influence at least three barriers in technological aspects. Four stakeholders have high power over organizational barriers (F3, F6, F8, F9, and F10), including S1 (the government), S2 (developers), S7 (manufacturers) and S8 (researchers). In terms of the market and social barriers (F7, F11, F12 and F13), five stakeholders possessed higher power, namely S1 (the government), S2 (developers), S8 (researchers), S13 (the public), and S15 (the media).

Table 4. The adjacency matrix of the stakeholder-barriers network

\begin{tabular}{lcccccccccccccc}
\hline & $F 1$ & $F 2$ & $F 3$ & $F 4$ & $F 5$ & $F 6$ & $F 7$ & $F 8$ & $F 9$ & $F 10$ & $F 11$ & F12 & F13 & SUM \\
S1 & 1 & 1 & 1 & 1 & 0 & 1 & 1 & 1 & 1 & 1 & 1 & 1 & 1 & 12 \\
S2 & 1 & 1 & 0 & 1 & 1 & 1 & 1 & 1 & 1 & 1 & 1 & 1 & 0 & 11 \\
S3 & 1 & 1 & 0 & 1 & 1 & 1 & 1 & 1 & 1 & 0 & 0 & 0 & 0 & 8 \\
S4 & 1 & 1 & 0 & 1 & 1 & 1 & 1 & 1 & 1 & 0 & 0 & 0 & 0 & 8 \\
S5 & 1 & 1 & 0 & 1 & 1 & 1 & 1 & 1 & 1 & 0 & 0 & 0 & 0 & 8 \\
S6 & 0 & 1 & 0 & 1 & 0 & 1 & 1 & 1 & 1 & 0 & 0 & 0 & 0 & 6 \\
S7 & 1 & 1 & 1 & 1 & 1 & 1 & 1 & 1 & 1 & 0 & 0 & 0 & 0 & 9 \\
S8 & 0 & 0 & 1 & 1 & 1 & 0 & 1 & 1 & 1 & 0 & 0 & 1 & 1 & 8 \\
S9 & 0 & 0 & 0 & 0 & 0 & 1 & 0 & 0 & 1 & 0 & 0 & 1 & 1 & 4 \\
S10 & 0 & 0 & 0 & 1 & 1 & 1 & 0 & 0 & 1 & 1 & 0 & 0 & 0 & 5 \\
S11 & 0 & 0 & 0 & 0 & 0 & 1 & 0 & 0 & 1 & 0 & 0 & 0 & 1 & 3 \\
S12 & 1 & 0 & 1 & 0 & 0 & 0 & 0 & 1 & 0 & 0 & 0 & 1 & 1 & 5 \\
S13 & 1 & 0 & 0 & 0 & 0 & 0 & 0 & 0 & 0 & 0 & 1 & 1 & 1 & 4 \\
S14 & 0 & 1 & 0 & 0 & 1 & 1 & 0 & 1 & 0 & 0 & 0 & 0 & 0 & 4 \\
S15 & 1 & 0 & 0 & 0 & 0 & 0 & 0 & 0 & 1 & 1 & 1 & 1 & 1 & 6 \\
SUM & 9 & 8 & 4 & 9 & 8 & 11 & 8 & 10 & 12 & 4 & 4 & 7 & 7 & \\
\hline
\end{tabular}

Notes: S1=The government, S2=Developers, S3=Designers, S4=Contractors, S5=Professional sub-contractors, S6=Supervisors, S7=Manufacturers, S8=Researchers, S9=Education institutions, S10=Consultants, S11=Suppliers of equipment and materials, S12=Financial institutions, S13=The public, S14=Logistic enterprises, S15=The media.

By converting the stakeholder-barrier matrix into a barrier-barrier matrix, as shown in Table 5, 
resource similarity for the barriers can be examined. All of the values in the barrier-barrier matrix are larger than 1 . This suggests that each pair of barriers can be addressed by at least one stakeholder group. The matrix suggests that ten stakeholder groups have the power to influence both barrier F6 (dominance of conventional project process) and F9 (lack of knowledge and expertise), and nine stakeholder groups have the power to influence both barrier F4 (quality issues) and F9 (lack of knowledge and expertise). This implies that these pairs of barriers have high resource similarity, requiring the actions of similar stakeholder groups. Similarly, the matrix indicates several pairs of barriers with the least resource similarity, such as F2 (ineffective logistics) and F13 (inadequate policies and regulations), as well as F3 (poor manufacturing capability) and F10 (inappropriate business model). This suggests that these pairs of barriers are very different from each other and require different stakeholders' actions to tackle.

Table 5. Barrier-barriers matrix

\begin{tabular}{llllllllllllll}
\hline & F1 & F2 & F3 & F4 & F5 & F6 & F7 & F8 & F9 & F10 & F11 & F12 & F13 \\
F1 & 9 & & & & & & & & & & & & \\
F2 & 6 & 8 & & & & & & & & & & & \\
F3 & 3 & 2 & 4 & & & & & & & & & & \\
F4 & 6 & 7 & 3 & 9 & & & & & & & & & \\
F5 & 5 & 6 & 2 & 7 & 8 & & & & & & & & \\
F6 & 6 & 8 & 2 & 8 & 7 & 11 & & & & & & & \\
F7 & 6 & 7 & 3 & 8 & 6 & 7 & 8 & & & & & & \\
F8 & 7 & 8 & 4 & 8 & 7 & 8 & 8 & 10 & & & & & \\
F9 & 7 & 7 & 3 & 9 & 7 & 10 & 8 & 8 & 12 & & & \\
F10 & 3 & 2 & 1 & 3 & 2 & 3 & 2 & 2 & 4 & 4 & & & \\
F11 & 4 & 2 & 1 & 2 & 1 & 2 & 2 & 2 & 3 & 3 & 4 & & \\
F12 & 5 & 2 & 3 & 3 & 2 & 3 & 3 & 4 & 5 & 3 & 4 & 7 & \\
F13 & 4 & 1 & 3 & 2 & 1 & 3 & 2 & 3 & 5 & 2 & 3 & 6 & 7 \\
\hline
\end{tabular}

Similarly, the stakeholder-stakeholder matrix presents the number of barriers that the pairs of stakeholder groups have the power to address. As shown in Table 6, the power similarity between S1 (the government) and S2 (developers) is the highest of all the stakeholder pairs. Both S1 and S2 have the power to influence ten barriers accounting for nearly $80 \%$ of the total number of barriers. The stakeholders of S3 (designers), S4 (contractors), S5 (sub-contractors), and S7 (manufacturers) also have high power similarity. In contrast, there are five pairs of stakeholders with no identical barriers that particular stakeholders have the power to address, namely S6 (supervisors) and S13 (the media), S10 (education institutions) and S12 (suppliers of equipment and material), S10 (education institutions) and S13 (financial institutions), S13 (financial institutions) and S14 (logistic enterprises), and finally S14 (logistic enterprises) and S15 (the media). These stakeholder pairs deal with different barriers. 
Table 6. Stakeholder-stakeholder matrix

\begin{tabular}{llllllllllllllll}
\hline & S1 & S2 & S3 & S4 & S5 & S6 & S7 & S8 & S9 & S10 & S11 & S12 & S13 & S14 & S15 \\
S1 & 12 & & & & & & & & & & & & & & \\
S2 & 10 & 11 & & & & & & & & & & & & \\
S3 & 7 & 8 & 8 & & & & & & & & & & & \\
S4 & 7 & 8 & 8 & 8 & & & & & & & & & & \\
S5 & 7 & 8 & 8 & 8 & 8 & & & & & & & & & & \\
S6 & 6 & 6 & 6 & 6 & 6 & 6 & & & & & & & & & \\
S7 & 8 & 8 & 8 & 8 & 8 & 6 & 9 & & & & & & & \\
S8 & 7 & 6 & 5 & 5 & 5 & 4 & 6 & 8 & & & & & & & \\
S9 & 4 & 3 & 2 & 2 & 2 & 2 & 2 & 3 & 4 & & & & & \\
S10 & 4 & 5 & 4 & 4 & 4 & 3 & 4 & 3 & 2 & 5 & & & & \\
S11 & 3 & 2 & 2 & 2 & 2 & 2 & 2 & 2 & 3 & 2 & 3 & & & \\
S12 & 5 & 3 & 2 & 2 & 2 & 1 & 3 & 4 & 2 & 0 & 1 & 5 & & & \\
S13 & 4 & 3 & 1 & 1 & 1 & 0 & 1 & 2 & 2 & 0 & 1 & 3 & 4 & & \\
S14 & 3 & 4 & 4 & 4 & 4 & 3 & 4 & 2 & 1 & 2 & 1 & 1 & 0 & 4 & \\
S15 & 6 & 5 & 2 & 2 & 2 & 1 & 2 & 3 & 3 & 2 & 2 & 3 & 4 & 0 & 6 \\
\hline & & & & & & & & & & & & & & \\
\end{tabular}

\subsection{Visualizing the stakeholder-barrier network}

The visualization of the stakeholder-barrier network generated by UNCIT is presented by Fig. 2. In the graph, stakeholders and barriers were represented by red nodes and blue nodes respectively. Three attributes of the network have been analyzed, namely degree centrality, betweenness centrality, and eigenvector centrality.

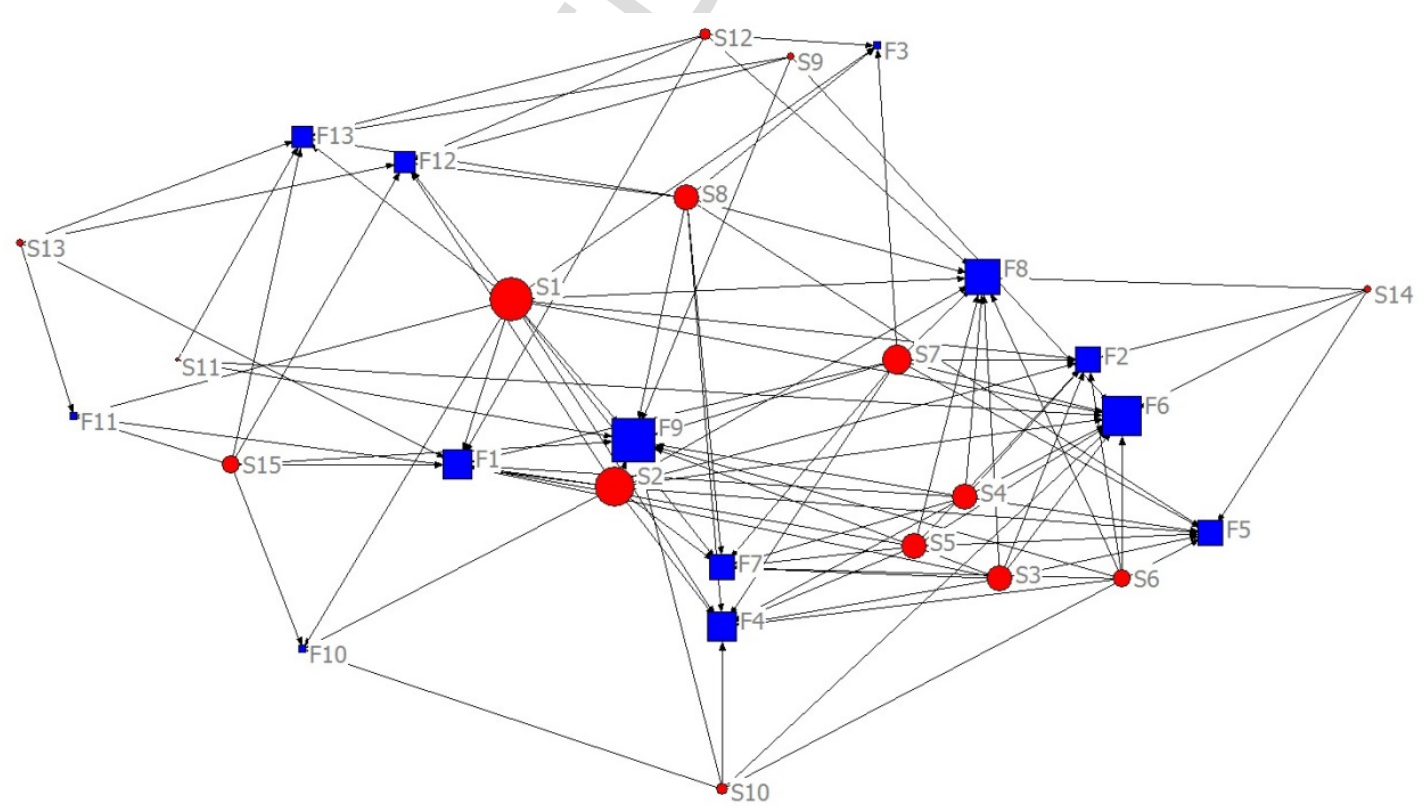

Fig.2. Visualization of the stakeholder-barrier network

The degree centrality is reflected by the size of nodes in Fig. 2. The larger size of nodes represents 
higher degree centrality. As shown in Table 7, the two stakeholder groups with the highest degree centrality are S1 (the government) and S2 (developers). This suggests these two stakeholders have access to diverse resources to address many barriers. Other stakeholder groups with high centrality degree include S3 (designers), S4 (contractors), S5 (sub-contractors), S7 (manufacturers) and S8 (researchers), impacting at least 8 barriers. Three barriers with the highest degree centrality are F9 (lack of knowledge and expertise), F6 (the dominance of conventional project process), and F8 (complicated management). This reflects the high complexity of addressing these barriers as more stakeholders are involved. Three barriers with the least degree centrality are F3 (poor manufacturing capability), F10 (inappropriate business model) and F11 (limited market demand).

Table 7. The centrality of nodes in the stakeholder-barrier network

\begin{tabular}{cccccccccccccc}
\hline Stakeholders & DC & Rank & BC & Rank & EC & Rank & Barriers & DC & Rank & BC & Rank & EC & Rank \\
\hline S1 & 12 & 1 & 46.71 & 1 & 0.28 & 1 & F1 & 9 & 4 & 25.47 & 3 & 0.21 & 6 \\
\hline S2 & 11 & 2 & 33.65 & 2 & 0.28 & 1 & F2 & 8 & 5 & 10.00 & 9 & 0.21 & 6 \\
\hline S3 & 8 & 4 & 9.16 & 5 & 0.24 & 3 & F3 & 4 & 7 & 2.81 & 13 & 0.10 & 10 \\
\hline S4 & 8 & 4 & 9.16 & 5 & 0.24 & 3 & F4 & 9 & 4 & 13.06 & 7 & 0.23 & 4 \\
\hline S5 & 8 & 4 & 9.16 & 5 & 0.24 & 3 & F5 & 8 & 5 & 11.68 & 8 & 0.19 & 7 \\
\hline S6 & 6 & 5 & 4.02 & 8 & 0.18 & 5 & F6 & 11 & 2 & 32.41 & 2 & 0.25 & 2 \\
\hline S7 & 9 & 3 & 15.84 & 4 & 0.25 & 2 & F7 & 8 & 5 & 8.41 & 10 & 0.22 & 5 \\
\hline S8 & 8 & 4 & 18.12 & 3 & 0.19 & 4 & F8 & 10 & 3 & 22.53 & 4 & 0.24 & 3 \\
\hline S9 & 4 & 7 & 3.85 & 9 & 0.10 & 8 & F9 & 12 & 1 & 39.43 & 1 & 0.27 & 1 \\
\hline S10 & 5 & 6 & 4.99 & 7 & 0.13 & 6 & F10 & 4 & 7 & 3.61 & 12 & 0.09 & 11 \\
\hline S11 & 3 & 8 & 1.93 & 11 & 0.08 & 9 & F11 & 4 & 7 & 3.92 & 11 & 0.09 & 11 \\
\hline S12 & 5 & 6 & 6.06 & 6 & 0.10 & 8 & F12 & 7 & 6 & 14.29 & 6 & 0.13 & 8 \\
\hline S13 & 4 & 7 & 2.98 & 10 & 0.07 & 10 & F13 & 7 & 6 & 16.38 & 5 & 0.11 & 9 \\
\hline S14 & 4 & 7 & 1.69 & 12 & 0.12 & 7 & & & & & & \\
\hline S15 & 6 & 5 & 9.66 & 5 & 0.12 & 7 & & & & & & \\
\hline Notes: & & & & & & & & & & & \\
\hline
\end{tabular}

Notes: $\mathrm{DC}=$ degree centrality, $\mathrm{BC}=$ betweenness centrality, $\mathrm{EC}=$ eigenvector centrality.

Regarding the betweenness centrality, stakeholders with the highest scores include S1 (the government), S2 (developers), S7 (manufacturers) and S8 (researchers). High betweenness centrality of these stakeholders indicate that they possess prominent positions in the network, act as mediators, and can exert considerable influence on OSC barriers. Barriers with higher betweenness centrality include F9 (lack of knowledge and expertise). F6 (dominance of traditional project process), F1 (high cost) and F8 (complicated management). This indicates more stakeholders groups can address these barriers. Similarly, regarding the eigenvector centrality, stakeholders with the highest score are also S1 (the government) and S2 (developers), and the top three barriers with the highest eigenvector centrality are F9 (lack of knowledge and expertise), F6 (dominance of traditional project process), and F8 (complicated management). The ranking of eigenvector centrality is generally in line with degree centrality. This is consistent with Sankar et 
al. (2015), who suggested that the degree and eigenvector centrality are strongly correlated. The identified stakeholders and barriers with high centralities can be regarded as the most critical ones that have significant impacts on OSC.

\subsection{Core-periphery structure of the stakeholder-barrier network}

The results of the core-periphery model analysis are represented by the density matrix (Table 8 ). The final fitness of 0.842 implies the real structure of stakeholder-barrier network highly approximates that of an ideal core/periphery structure. The density of interactions between core stakeholders and barriers is 0.814 , which suggests that intensive relationships exist between stakeholders and barriers in the core position. The partial densities of the intersections between core stakeholders and periphery barriers, and between core barriers and periphery stakeholders are 0.059 and 0.16 respectively. This indicates that the core stakeholders are loosely connected to the peripheral barriers, and the core barriers are loosely connected to the peripheral stakeholders as well. Therefore, it can be argued that the stakeholder-barrier network presents a core-periphery structure.

Table 8. Density matrix

\begin{tabular}{|c|c|c|c|}
\hline \multirow{4}{*}{ Stakeholder } & & \multicolumn{2}{|c|}{ Barrier } \\
\hline & & Core & Periphery \\
\hline & Core & 0.814 & 0.059 \\
\hline & Periphery & 0.16 & 0.014 \\
\hline
\end{tabular}

The core stakeholders and barriers are identified in Fig 3. Seven stakeholders and ten barriers are located in the core position, denoted by the top left corner. The seven core stakeholders include S1 (the government), S2 (developers), S3 (designers), S4 (contractors), S5 (sub-contractors), S7 (manufacturers), and S8 (researchers). Ten barriers are found to be in the core position, accounting for nearly $80 \%$ of the total barriers, except the barriers of F3, F10, and F11. As these core barriers are more likely to be addressed by core stakeholders, the dense interactions between core stakeholders can happen. This facilitates information flow among these core stakeholders who could contribute to the formation of shared values, attitudes and interests towards OSC. 


\begin{tabular}{|c|c|c|c|c|c|c|c|c|c|c|c|c|c|}
\hline & F7 & F1 & $\mathbf{F 2}$ & F6 & F4 & F5 & F9 & F13 & F8 & F12 & F3 & F10 & F11 \\
\hline S1 & 1 & 1 & 1 & 1 & 1 & & 1 & 1 & 1 & 1 & 1 & 1 & 1 \\
\hline S2 & 1 & 1 & 1 & 1 & 1 & 1 & 1 & & 1 & 1 & & 1 & 1 \\
\hline S3 & 1 & 1 & 1 & 1 & 1 & 1 & 1 & & 1 & & & & \\
\hline S4 & 1 & 1 & 1 & 1 & 1 & 1 & 1 & & 1 & & & & \\
\hline S5 & 1 & 1 & 1 & 1 & 1 & 1 & 1 & & 1 & & & & \\
\hline S7 & 1 & 1 & 1 & 1 & 1 & 1 & 1 & & 1 & & 1 & & \\
\hline S8 & 1 & & & 1 & 1 & 1 & 1 & 1 & 1 & 1 & 1 & & \\
\hline S6 & 1 & & 1 & 1 & 1 & & 1 & & 1 & & & & \\
\hline S9 & & & & 1 & & & 1 & 1 & & 1 & & & \\
\hline S10 & & & & 1 & 1 & 1 & 1 & & & & & 1 & \\
\hline S11 & & & & 1 & & & 1 & 1 & & & & & \\
\hline S12 & & 1 & & & & & & 1 & 1 & 1 & 1 & & \\
\hline S13 & & 1 & & & & & & 1 & & 1 & & & 1 \\
\hline S14 & & & 1 & 1 & & 1 & & & & & & & \\
\hline S15 & & 1 & & & & & 1 & 1 & & 1 & & 1 & 1 \\
\hline
\end{tabular}

Fig.3. Core-periphery structure model of stakeholder-barrier network

The core-periphery structure identified in this study provides instructions on how to develop an active stakeholder collaborative network. For instance, S1 (the government) situated in the core position, has the power to address 12 barriers, among which nine barriers are located in the core position and three barriers are located in the periphery position. The nine core barriers are more likely to be addressed by the core stakeholders, as indicated in Fig. 3. Therefore, collaborations should be developed between these core stakeholders and S1 (the government). Due to the higher centrality indices, S1 (the government) should play a critical intermediary role in fostering the collaborative partnerships between these core stakeholders. The eight periphery stakeholders listed in the lower left corner of Fig. 3 also have some power to address these core barriers, even though the influence is weaker than the core stakeholders. Thus, when tackling the core barriers, the core stakeholders could also construct collaborative relationships with the periphery stakeholders. Regarding the three periphery barriers, they could be tackled not only by the core stakeholders but also by periphery stakeholders. For instance, as shown in Fig. 3, one periphery stakeholder namely S12 (financial institutions) has the power to influence F3 (poor manufacturer capability), which can be addressed by three core stakeholders, namely S1 (the government), S7 (manufacturers) and S8 (researchers).

\section{Discussions}

With the emerging trend of adopting OSC worldwide, a few studies have been conducted on OSC 
from various perspectives. Despite this, the issue of stakeholder collaboration as the key to promoting OSC adoption has been overlooked and who has the power to address which barrier remains unclear. It is stakeholder collaboration that can aggregate the required knowledge, material, technology and other resources highly dispersed across various stakeholder groups to address the barriers to OSC adoption. Previous studies mainly focused on the identification and ranking of the barriers to OSC based on statistical analysis such as factor analysis (Mao et al., 2015; Zhai et al., 2014), as well as importance (mean) calculation (Polat, 2010). By linking the identified 13 barriers with 15 stakeholders through stakeholder-barrier analysis, this research provides an innovative perspective to explore stakeholder collaboration in the OSC adoption. The results of two-mode social network analysis revealed that each barrier is linked with at least four groups of stakeholders, up to a maximum 12 stakeholders. In accordance with Rutten et al. (2009), this reaffirmed the importance of stakeholder collaboration in the diffusion of innovative technology in the construction industry, based on our findings from Chongqing. As a projectbased industry characterized by fragmentation and conservatism, the construction industry requires stakeholder collaboration to form relatively stable innovation networks to enable the diffusion of innovation, such as OSC (Xue et al., 2017).

The stakeholder-barrier matrix presented the power distribution of each stakeholder over each barrier. According to Table 4 (earlier), compared to other barriers, organizational barriers can be addressed by the highest number of stakeholders, with an average of nine stakeholders per barrier. Similarly, each technological barrier and social barrier can be addressed by eight and six stakeholders respectively on average. Each stakeholder has its own interests, which might conflict with each other, and thus it is a tough task to coordinate different stakeholders to adopt OSC. Linked with most stakeholders are three organizational barriers, including F9 (lack of knowledge and expertise), F8 (complicated management) and F6 (dominance of conventional project process). This suggests the complexity of addressing the organizational barriers, since more stakeholders are required to address and coordinate these barriers without compromising their efforts to tackle other barriers. This finding complements previous studies that rank other issues such as higher cost and lacking governmental incentives as the most critical barriers without considering the complexity of stakeholders' influencing power (Mao et al., 2015; Zhang et al., 2014).

Furthermore, tackling multiple barriers is also a challenge for stakeholders as their resources are limited. By showing the relationships among barriers, the barrier-barrier matrix contributes to the decision making of OSC. For instance, the most common stakeholders were connected to the barrier pairs of F9 (lacking knowledge and expertise) and F6 (dominance of conventional project 
process). This indicates that the adoption of OSC, requiring the reformulation of the project completion process, could be a significant challenge to related stakeholders whose knowledge background is rooted in the conventional cast in-situ method. Therefore, education and training on not only the technical aspects of OSC but also the associated changes of project management should be conducted for employees in construction enterprises adopting OSC.

As shown in Table 4, seven stakeholders have the power to address at least eight barriers, accounting for more than $60 \%$ of the total barriers. These stakeholders include S1 (the government), S2 (developers), S3 (designers), S4 (contractors), S5 (sub-contractors), S7 (manufacturers) and S8 (researchers). Among these stakeholders, special attention should be paid to S7 (manufacturers), who were often overlooked in conventional on-site construction approaches. According to Mao et al. (2015), lacking manufacturers of prefabricated components is a critical issue in China. Due to the absence of qualified manufacturers, developers or contractors have to produce the prefabricated components by themselves increasing not only the cost burden but also the complexity of management (Zhang et al., 2014). Similarly, the importance of S8 (researchers) also needs to be highlighted. As Reichstein et al. (2005) indicated, due to the low entry threshold, the construction industry has been regarded as a low-technology sector with inadequate investment in research and development activities. For instance, in the Chinese construction industry, the investment in research and development activities account for as little as $0.4 \sim 0.6 \%$ of the GDP generated by the industry (Gan et al., 2015). As researchers (S8) have the power to impact eight barriers, the government should provide more research funding for researchers specialized in OSC. Furthermore, according to Table 6, the stakeholder pairs that have the highest common barriers to deal with are often formed by S1 (the governments), S2 (developers), S3 (designers), S4 (contractors), S5 (sub-contractors), S6 (supervisors), S7 (manufacturers) and S8 (researchers). This indicates that these stakeholders should particularly develop collaborative relationships to promote OSC adoption.

Visualizing the stakeholder-barrier adjacency matrix, as shown in Fig. 2, displays the network structures of stakeholder collaboration for eliminating the barriers to OSC. The results of the centrality analysis of stakeholder-barrier network highlight two stakeholders, namely S1 (the government) and S2 (developers), who played the most significant role in the development of stakeholder collaboration. They were ranked as the top two stakeholders with the highest degree centrality and eigenvector centrality, indicating that they have great power to influence more barriers, and were situated in a more central position in the network. They were also perceived with the highest betweenness centrality, suggesting they can exert substantial influences on the exchanges of resources and information in the network. Therefore, the stakeholder-barrier network 
presents a dual-key network structure, indicating the stakeholder collaboration should be initiated by the two key stakeholders, namely S1 (the government) and S2 (developers). The Chinese government has actively facilitated the adoption of OSC through the issue of relevant goals and policies. For instance, in 2017, the MOHURD has issued the "Action Plan of Promoting OSC Building Within the $13^{\text {th }}$ Five-Year Period", "Management Methods for Demonstration Cities for Prefabricated Buildings" and "Management Methods for Establishing Industrial Base of OSC" to promote OSC in the construction industry. Currently, the Chinese government's primary approach to encourage OSC is to establish demonstration and trial projects. As Zhang et al. (2011) highlighted, developers will actively participate in promoting green practices only if these practices can help them gain competitiveness in the market. Thus, it is recommended that not only demonstration projects of the OSC technology but also the successful business models of OSC should be developed and promoted through more interaction between the government and developers.

The core-periphery structure of the stakeholder network identified in this paper provides insights on how to develop a collaborative stakeholder network facilitating OSC adoption. Core stakeholders are often deeply immersed in the social network, in which they can leverage their credibility and gain the support from other stakeholders to protect new ideas from skeptical scrutiny (Cattani et al., 2008). In other words, once the core stakeholders have recognized OSC adoption, it is likely that the acceptance and legitimacy would be transmitted to periphery stakeholders. As Cattani et al. (2008) highlighted, stakeholders located at the core position play critical coordinating roles. Therefore, it is imperative to foster collaborative relationships between the core stakeholders. As shown in Table 7, with high degree centrality and betweenness centrality, these core stakeholders include S1 (the government), S2 (developers), S3 (designers), S4 (contractors), S5 (sub-contractors), S7 (manufacturers) and S8 (researchers). The two principal stakeholders, namely the government and developers, need to construct intensive collaborative relations with other core stakeholders. At the same time, to form a shared vision for OSC among these core stakeholders is also critical. An information exchange platform should be created by developers or governmental agencies to facilitate the communication among stakeholders, thereby shared values and attitudes towards OSC can be encouraged.

\section{Conclusions}

Although OSC has been regarded as a useful tool to address various challenges related to sustainability, it is still in its infancy in various countries, especially in developing countries like China. This research explores stakeholder's influencing power over various barriers to OSC 
adoption through two-mode social network analysis, which extends the traditional research paradigms of identifying and ranking the obstacles. Firstly, 13 barriers to OSC adoption as well as 15 stakeholder groups who have the power to address these barriers were identified. Then, the stakeholder' power status on each barrier was investigated using two-model social network analysis based on a questionnaire survey. The co-attended barriers of stakeholders and coaffiliated stakeholders of barriers were identified through analyzing the barrier-barrier matrix and stakeholder-stakeholder matrix. The network centrality indexes, including the degree centrality, betweenness centrality and eigenvector centrality were also examined, which identifies that the government and developers are the most influential stakeholders, and the lack of knowledge and expertise and the dominant conventional project processes are the most influential barriers in the network. Finally, by using the core-periphery model analysis, the core stakeholders and barriers, as well as the periphery stakeholders and barriers, were identified and investigated. Among the total of 15 stakeholders and 13 barriers, 8 stakeholders and 10 barriers were identified to be core in the network. The results not only clarify the stakeholder's power status over barriers but also reveal the network characteristics and structures of stakeholder collaboration. This study provides theoretical contributions and practical implications for promoting the OSC adoption.

Theoretically, this study is the first attempt to explore stakeholder collaboration in promoting OSC adoption. The research findings complement previous studies identifying the barriers to OSC adoption, by innovatively demonstrating the power of 15 stakeholders to address the barriers through the use of two-mode social network analysis, which has not been employed in previous studies on OSC. The core-periphery structure suggests various stakeholders play different roles in stakeholder collaboration. To develop effective stakeholder collaboration, the government and developers need to take the leading role in fostering the collaborative network, engaging other key stakeholders, such as designers, contractors and manufacturers, who then need to collaborate with the periphery stakeholders such as consultants and logistics enterprises. Developing an information exchange platform is strongly recommended to foster the formation of a shared vision of OSC among stakeholders, which could significantly facilitate stakeholder collaboration.

Practically, this study has important policy implications for promoting OSC adoption. As a high number of shared stakeholders were found in addressing technological and organizational barriers, it is important for stakeholders to wisely allocate their limited resources to ensure that both organizational and technological barriers are adequately addressed without neglecting some barriers. Furthermore, the critical roles of manufacturers and researchers in promoting OSC, which were often neglected in traditional on-site construction approaches, need to be emphasized by fostering the development of qualified manufacturers as well as providing more research 
funding for research institutions.

One limitation of this study is that the data was collected from practitioners in Chongqing, China. Since stakeholders' perceptions towards OSC may change along with time during the different development stages of OSC, the results of this study can only reflect the stakeholders' perceptions in the initial development stage of OSC. Therefore, the results of this study could be referred by other countries where OSC is similarly in the premature stage, such as Vietnam, Thailand and Brazil. With the growing acceptance and maturity level of OSC technology, stakeholders' perceptions towards OSC could become increasingly positive. Future studies need to be conducted in other countries, especially countries where OSC has become mature within the industry, so that the international benchmarking of OSC acceptance could be established. Future studies could also employ theories, such as social-technical transition theories (Zhao et al., 2016), to investigate the barriers to OSC. For countries where OSC is at the initial development stage, such as China, continuous studies on the OSC adoption are needed to dynamically monitor the stakeholders' changing attitude towards OSC, so that policies to promote OSC could be altered accordingly to keep up with the development of the industry.

\section{Acknowledgments}

This study is supported by the 2018 Faculty Research Grant of Bond University, China Postdoctoral Science Foundation (No.2017M6229950), Fundamental Research Funds for the Central Universities (No.SWU1809124) and (No.SWU1409101), Chongqing Social Science Foundation (No. 2017QNGL51) and Chongqing Postdoctoral Science Foundation (No. XM2017155). The authors would also like to thank Professor Craig Langston for helping edit this article.

\section{References}

Aitkin, M., Vu, D., \& Francis, B. (2014). Statistical modelling of the group structure of social networks. Social Networks, 38(1), 74-87.

Arditi, D., Ergin, U., \& Gunhan, S. (2000). Factors affecting the use of precast concrete systems. Journal of Architectural Engineering, 6(3), 79-86.

Arif, M., \& Egbu, C. (2010). Making a case for offsite construction in China. Engineering, Construction and Architectural Management, 17(6), 536-548.

Blismas, N., \& Wakefield, R. (2009). Drivers, constraints and the future of offsite manufacture in Australia. Construction Innovation, 9(1), 72-83.

Borgatti, S. P., \& Everett, M. G. (1997). Network analysis of 2-mode data. Social Networks, 19(3), 243-269.

Borgatti, S. P., \& Everett, M. G. (2000). Models of core/periphery structures. Social Networks, 21(4), 375-395.

Cattani, G., \& Ferriani, S. (2008). A Core/Periphery Perspective on Individual Creative Performance: Social Networks and Cinematic Achievements in the Hollywood Film Industry. Organization 
Science, $19(6), 824-844$.

Chang, R. D., Zuo, J., Soebarto, V., Zhao, Z. Y., Zillante, G., \& Gan, X. L. (2016). Sustainability Transition of the Chinese Construction Industry: Practices and Behaviors of the Leading Construction Firms. Journal of Management in Engineering, 32(4), 05016009.

Chang, R. D., Zuo, J., Soebarto, V., Zhao, Z. Y., Zillante, G., \& Gan, X. L. (2017). Discovering the Transition Pathways toward Sustainability for Construction Enterprises: ImportancePerformance Analysis. Journal of Construction Engineering \& Management, 143(6), 04017013.

Cheng, E. W. L., Li, H., Love, P. E. D., \& Irani, Z. (2001). Network communication in the construction industry. Corporate Communications An International Journal, 6(2), 61-70.

Chiang, Y. H., Chan, H. W., \& Lok, K. L. (2006). Prefabrication and barriers to entry - a case study of public housing and institutional buildings in Hong Kong. Habitat International, 30(3), 482499.

D’Esposito, M. R., Stefano, D. D., \& Ragozini, G. (2014). On the use of Multiple Correspondence Analysis to visually explore affiliation networks. Social Networks, 38(1), 28-40.

Darko, A., Zhang, C., \& Chan, A. P. C. (2017). Drivers for green building: A review of empirical studies. Habitat International, 60, 34-49.

Dewick, P., \& Miozzo, M. (2004). Networks and innovation: sustainable technologies in Scottish social housing. Social Science Electronic Publishing, 34(3), 323-333.

Elnaas, H., Ashton, P., \& Gidado, K. (2014). Factors and Drivers Effecting the Decision of Using OffSite Manufacturing (OSM) Systems in House Building Industry. Journal of Engineering Project \& Production Management, 4(1), 51-58.

Faust, K. (1997). Centrality in affiliation networks. Social Networks, 19(2), 157-191.

Freeman, L. C. (1978). Centrality in social networks conceptual clarification. Social Networks, 1(3), 215-239.

Gan, X., Zuo, J., Wu, P., Wang, J., Chang, R., \& Wen, T. (2017). How affordable housing becomes more sustainable? A Stakeholder Study. Journal of Cleaner Production, 162(20), 427-437.

Gan, X., Zuo, J., Ye, K., Skitmore, M., \& Xiong, B. (2015). Why sustainable construction? Why not? An owner's perspective. Habitat International, 47, 61-68.

Gao, S., \& Low, S. P. (Eds.). (2014). Lean construction management. Berlin.

Gaski, J. F. (1984). The Theory of Power and Conflict in Channels of Distribution. Journal of Marketing, 48(3), 9-29.

Hong, J., Shen, G. Q., Mao, C., Li, Z., \& Li, K. (2016). Life-cycle energy analysis of prefabricated building components: an input-output-based hybrid model. Journal of Cleaner Production, 112, 2198-2207.

Hwang, B. G., Shan, M., \& Looi, K. Y. (2018). Key Constraints and Mitigation Strategies for Prefabricated Prefinished Volumetric Construction. Journal of Cleaner Production, 183(10), 183-193.

Jaillon, L., \& Poon, C. S. (2008). Sustainable construction aspects of using prefabrication in dense urban environment: a Hong Kong case study. Construction Management and Economics, 26(9), 953-966.

Jaillon, L., \& Poon, C. S. (2010). Design issues of using prefabrication in Hong Kong building construction. Construction Management \& Economics, 28(10), 1025-1042.

Jeong, J. G., Hastak, M., \& Syal, M. (2009). Framework of manufacturer - retailer relationship in the 
manufactured housing construction. Construction Innovation, 9(1), 22-41.

Ji, Y., Zhu, F., Li, H. X., \& Al-Hussein, M. (2017). Construction Industrialization in China: Current Profile and the Prediction. Applied Sciences, 6(2), 1-13.

Jiang, R., Wu, C., Mao, C., \& Shrestha, A. (2016). Ecosystem Visualization and Analysis of Chinese Prefabricated Housing Industry. Procedia Engineering, 145, 436-443.

Kamali, M., \& Hewage, K. (2016). Development of performance criteria for sustainability evaluation of modular versus conventional construction methods. Journal of Cleaner Production, 142(4), 3592-3606.

Li, C. Z., Hong, J., Xue, F., Shen, G. Q., Xu, X., \& Mok, M. K. (2016). Schedule risks in prefabrication housing production in Hong Kong: a social network analysis. Journal of Cleaner Production, $134,482-494$.

Li, C. Z., Zhong, R. Y., Xue, F., Xu, G., Chen, K., Huang, G. G., \& Shen, G. Q. (2017). Integrating RFID and BIM technologies for mitigating risks and improving schedule performance of prefabricated house construction. Journal of Cleaner Production, 165(1), 1048-1062.

Li, H., Fang, W., An, H., \& Yan, L. L. (2014a). The shareholding similarity of the shareholders of the worldwide listed energy companies based on a two-mode primitive network and a one-mode derivative holding-based network. Physica A Statistical Mechanics \& Its Applications, 415, 525-532.

Li, Z., Shen, G. Q., \& Xue, X. (2014b). Critical review of the research on the management of prefabricated construction. Habitat International, 43(3), 240-249.

Lin, X., Ho, C. M. F., \& Shen, G. Q. P. (2017). Who should take the responsibility? Stakeholders' power over social responsibility issues in construction projects. Journal of Cleaner Production, 154(15), 318-329.

Liu, G., Li, K., Zhao, D., \& Mao, C. (2016). Business Model Innovation and Its Drivers in the Chinese Construction Industry during the Shift to Modular Prefabrication. Journal of Management in Engineering, 33(3), 04016051.

Liu, L. S., Shen, L. P., Jiang, Y., Han, Z. F., \& Hong, J. (2014). Measuring the impact of prefabrication on construction waste reduction: An empirical study in China. Resources Conservation \& Recycling, 91(5), 27-39.

Lovell, H., \& Smith, S. J. (2010). Agencement in housing markets: The case of the UK construction industry. Geoforum, 41(3), 457-468.

Lu, Y., Wu, Z., Chang, R., \& Li, Y. (2017). Building Information Modeling (BIM) for green buildings: A critical review and future directions. Automation in Construction, 83, 134-148.

Luo, L. Z., Mao, C., Shen, L. Y., \& Li, Z. D. (2015). Risk factors affecting practitioners' attitudes toward the implementation of an industrialized building system: A case study from China. Engineering, Construction and Architectural Management, 22(6), 622-643.

Malik, H. A. M., Mahesar, A. W., Abid, F., Waqas, A., \& Wahiddin, M. R. (2017). Two-mode network modeling and analysis of dengue epidemic behavior in Gombak, Malaysia. Applied Mathematical Modelling, 43, 207-220.

Mao, C., Shen, Q., Pan, W., \& Ye, K. (2015). Major Barriers to Off-Site Construction: The Developers' Perspective in China. Journal of Management in Engineering, 31(3), 04014043.

Mao, C., Shen, Q., Shen, L., \& Tang, L. (2013). Comparative study of greenhouse gas emissions between off-site prefabrication and conventional construction methods: Two case studies of residential projects. Energy \& Buildings, 66(5), 165-176. 
Mao, C., Xie, F., Hou, L., Wu, P., Wang, J., \& Wang, X. (2016). Cost analysis for sustainable off-site construction based on a multiple-case study in China. Habitat International, 57, 215-222.

Martinus, K., Sigler, T. J., Searle, G., \& Tonts, M. (2015). Strategic globalizing centers and subnetwork geometries: A social network analysis of multi-scalar energy networks. Geoforum, 64, 78-89.

Missonier, S., \& Loufrani-Fedida, S. (2014). Stakeholder analysis and engagement in projects: From stakeholder relational perspective to stakeholder relational ontology. International Journal of Project Management, 32(7), 1108-1122.

Mitchell, R. K., Agle, B. R., \& Wood, D. J. (1997). Toward a Theory of Stakeholder Identification and Salience: Defining the Principle of who and What Really Counts. Academy of Management Review, 22(4), 853-886.

Muinz García, A. S., \& Carvajal, C. R. (2006). Core/periphery structure models: An alternative methodological proposal. Social Networks, 28(4), 442-448.

Nadim, W., \& Goulding, J. S. (2010). Offsite production in the UK: the way forward? A UK construction industry perspective. Construction Innovation, 10(2), 181-202.

Nadim, W., \& Goulding, J. S. (2011). Offsite production: a model for building down barriers: A European construction industry perspective. Engineering, Construction and Architectural Management, 18(1), 82-101.

O'Neill, D., \& Organ, S. (2016). A literature review of the evolution of British prefabricated low-rise housing. Structural Survey, 2(34), 191-214.

Olubunmi, O. A., Xia, P. B., \& Skitmore, M. (2016). Green building incentives: A review. Renewable \& Sustainable Energy Reviews, 59, 1611-1621.

Pan, W., Dainty, A. R. J., \& Gibb, A. G. F. (2012a). Establishing and Weighting Decision Criteria for Building System Selection in Housing Construction. Journal of Construction Engineering \& Management, 138(11), 1239-1250.

Pan, W., Gibb, A. G. F., \& Dainty, A. R. J. (2008). Leading UK housebuilders' utilization of offsite construction methods. Building Research \& Information, 36(1), 56-67.

Pan, W., \& Goodier, C. I. (2012b). House-Building Business Models and Off-Site Construction TakeUp. Journal of Architectural Engineering, 18(2), 84-93.

Polat, G. (2008). Factors Affecting the Use of Precast Concrete Systems in the United States. Journal of Construction Engineering \& Management, 134(3), 169-178.

Polat, G. (2010). Precast concrete systems in developing vs. industrialized countries. Journal of Civil Engineering \& Management, 16(1), 85-94.

Rahman, M. M. (2013). Barriers of Implementing Modern Methods of Construction. Journal of Management in Engineering, 30(1), 69-77.

Reichstein, T., Gann, A. J. S., \& M., D. (2005). Last among equals: a comparison of innovation in construction, services and manufacturing in the UK. Construction Management \& Economics, 23(6), 631-644.

Rowley, T. J. (1997). Moving beyond Dyadic Ties: A Network Theory of Stakeholder Influences. Academy of Management Review, 22(4), 887-910.

Rutten, M. E. J., Dorée, A. G., \& Halman, J. I. M. (2009). Innovation and interorganizational cooperation: a synthesis of literature. Construction Innovation, 9(3), 286-297.

Saito, H., \& Ruhanen, L. (2017). Power in tourism stakeholder collaborations: Power types and power holders. Journal of Hospitality \& Tourism Management, 31, 189-196. 
Sankar, C. P., Asokan, K., \& Kumar, K. S. (2015). Exploratory social network analysis of affiliation networks of Indian listed companies. Social Networks, 43, 113-120.

Shen, L., Song, X., Wu, Y., Liao, S., \& Zhang, X. (2016). Interpretive Structural Modeling based factor analysis on the implementation of Emission Trading System in the Chinese building sector. Journal of Cleaner Production, 127(20), 214-227.

Shi, Q., Yu, T., \& Zuo, J. (2015). What leads to low-carbon buildings? A China study. Renewable \& Sustainable Energy Reviews, 50, 726-734.

Steinhardt, D. A., Manley, K., \& Miller, W. (2013). Reshaping housing: the role of prefabricated systems. Building Construction Management \& Project Planning, 25(10), 1-28.

Tam, V. W. Y., Tam, C. M., Zeng, S. X., \& Ng, W. C. Y. (2007). Towards adoption of prefabrication in construction. Building \& Environment, 42(10), 3642-3654.

Teng, Y., Mao, C., Liu, G., \& Wang, X. (2017). Analysis of stakeholder relationships in the industry chain of industrialized building in China. Journal of Cleaner Production, 152(20), 387-398.

Tiew, F., Holmes, K., Bussy, N. D., Lockstonebinney, L., Holmes, K., \& Robertson, M. (2015). Tourism events and the nature of stakeholder power. Event Management, 19(4), 525-541.

Weng, C. S., Yang, W.-G., \& Lai, K.-K. (2014). Technological position in alliances network. Technology Analysis \& Strategic Management, 26(6), 669-685.

Wood, D. J., \& Gray, B. (1991). Toward a Comprehensive Theory of Collaboration. Journal of Applied Behavioral Science A Publication of the Ntl Institute, 27(2), 139-162.

Xue, X., Zhang, R., Yang, R., \& Dai, J. (2014). Innovation in Construction: A Critical Review and Future Research. International Journal of Innovation Science, 6(2), 111-126.

Xue, X., Zhang, X., Wang, L., Skitmore, M., \& Wang, Q. (2017). Analyzing collaborative relationships among industrialized construction technology innovation organizations: a combined SNA and SEM approach. Journal of Cleaner Production, 173(1), 265-277.

Zhai, X., Reed, R., \& Mills, A. (2014). Factors impeding the offsite production of housing construction in China: an investigation of current practice. Construction Management \& Economics, 32(1), 40-52.

Zhang, X., Shen, L., \& Wu, Y. (2011). Green strategy for gaining competitive advantage in housing development: a China study. Journal of Cleaner Production, 19(2-3), 157-167.

Zhang, X., Skitmore, M., \& Peng, Y. (2014). Exploring the challenges to industrialized residential building in China. Habitat International, 41(41), 176-184.

Zhao, Z.-Y., Chang, R.-D., \& Chen, Y.-L. (2016). What hinder the further development of wind power in China?-A socio-technical barrier study. Energy Policy, 88, 465-476.

Zhu, B., Watts, S., \& Chen, H. (2010). Visualizing social network concepts. Decision Support Systems, 49(2), 151-161. 


\section{Highlights:}

- 13 barriers and 15 stakeholders relevant to the OSC adoption were identified.

- Two-mode social network was adopted to link the stakeholders and barriers.

- Centrality and core-periphery structure analyses were adopted to study the network.

- Strategies were proposed to promote OSC adoption by stakeholder collaboration. 